Research Article

\title{
3D Processing Maps of Cast Mg-9Gd-3Y Alloy and Numerical-Experimental Verification
}

\author{
Pan $\mathrm{Li} \mathbb{D}^{1,2}$ and Jianguo Luo $\mathbb{D}^{1,2}$ \\ ${ }^{1}$ College of Mechanical and Electrical Engineering, North China Institute of Science and Technology, Langfang 065201, China \\ ${ }^{2}$ Hebei Key Laboratory of Safety Monitoring of Mining Equipment, Langfang 065201, China \\ Correspondence should be addressed to Pan Li; lipanedu@139.com
}

Received 12 February 2021; Revised 17 June 2021; Accepted 1 July 2021; Published 12 July 2021

Academic Editor: Guosong Wu

Copyright ( $) 2021$ Pan Li and Jianguo Luo. This is an open access article distributed under the Creative Commons Attribution License, which permits unrestricted use, distribution, and reproduction in any medium, provided the original work is properly cited.

\begin{abstract}
The hot compression behavior of Mg-9Gd-3Y (GW93) alloy was investigated by carrying out isothermal compression tests at the deformation temperature range of $300-450^{\circ} \mathrm{C}$ and strain rate range of $0.001-1 \mathrm{~s}^{-1}$. Considering the influence of the strain on the formability of the GW93 alloy, three-dimensional (3D) processing maps were established based on the dynamic material model. The $3 \mathrm{D}$ processing maps indicate that the formability of the material improved with the decrease of the strain rate and the increase of the heating temperature, and the material at lower heating temperature mostly underwent flow instability. The formable processing region of the hot deformation of the GW93 alloy was concentrated within the temperature range of $380-450^{\circ} \mathrm{C}$ and the strain rate range of $0.001-0.01 \mathrm{~s}^{-1}$. Subsequently, the 3D processing maps were embedded into the finite element (FE) software DEFORM-3D by means of user subroutines, and the formability of GW93 alloy during the isothermal plane strain forging process was predicted. The FE simulation results revealed that the formability of the material at low strain rate improved compared with that at high strain rate under the same temperature. Finally, an isothermal plane strain forging technological experiment was carried out, and the microstructure of the formed sample was analyzed. The experimental result is in good agreement with that of the numerical simulation. Combined with microstructural observation, the accuracy of the simulation results and the 3D processing maps of the GW93 alloy was verified.
\end{abstract}

\section{Introduction}

With the continuous development of precision plastic forming technology, the requirements of the hot forging process in the metal products industry are increasingly becoming stricter. Light weight and safety have become important standards for assessing the quality of metal forging products [1-4]. Magnesium alloy is a new type of metal material with extensive development potential and has the advantages of light weight, high specific strength and stiffness, good dimensional stability, easy processing, and recycling ability $[5,6]$. Presently, the concept of using magnesium alloys in the manufacturing of equipment parts is very popular in the automotive industry, aerospace, weapons equipment manufacturing, and other fields [7, 8]. Nevertheless, there are few plastic forming products, owing to the low mechanical properties of current commercial magnesium alloys in various series, and the main products of this material type are various casting types $[9,10]$. In recent years, many studies have shown that the mechanical properties of magnesium alloys can be significantly improved by adding high strength rare earth elements $[11,12]$. The tensile strength of the Mg-Gd-Y alloy subjected to hot deformation and aging treatment has exceeded $500 \mathrm{MPa}$ at room temperature, which indicates that it is possible to manufacture the plastic forming products of magnesium alloys $[13,14]$.

However, the results obtained by previous studies reveal that the poor formability and narrow processing temperature range of high strength rare earth magnesium alloys severely restrict their application and promotion [15]. However, with the aid of material physical models and 
processing maps, the formability of high strength rare earth magnesium alloys can be predicted and the optimal technological parameters can be obtained to replace the traditional trial and error method, which provides a reliable guarantee for the accurate control of product quality $[16,17]$. To date, many experiments have been carried out using this method to predict the forming ability of commercial magnesium alloys and the main prediction method is to establish two-dimensional processing maps based on the strain rate and temperature. Xin et al. [18] optimized and identified the hot pressing process parameters of the AZ31 magnesium alloy by establishing hot processing maps. By exploiting different instability criteria, Li et al. [19] established the instability maps, and the validity of the instability maps was verified through metallographic observation. The hot deformation behavior of extruded ZK60 magnesium alloy was investigated by establishing the processing maps, and it was verified that the hot extrusion process can effectively improve the workability of the alloy [20]. Anbuselvan and Ramanathan [21] investigated the hot deformation behavior and microstructure evolution of extruded ZE41A magnesium alloy using processing maps, and they found that the optimal process parameters for the hot working of the material are $400^{\circ} \mathrm{C}$ and $0.1 \mathrm{~s}^{-1}$. Based on FE simulation and three-dimensional (3D) processing maps, Liu et al. [22] proposed a new method for material driven analysis, and the effectiveness of this method was verified through a hot forging experiment using forging gear with the AZ31B alloy. However, the establishment of 3D processing maps including strain for investigating the hot deformation behavior of materials has rarely been reported.

In this study, the cast GW93 alloy was considered as the research object. First, based on isothermal compression tests, the $3 \mathrm{D}$ processing maps were established, and the effects of different process parameters on the hot formability of the GW93 alloy were investigated. Subsequently, a method combining FE simulation and microstructural observation was applied to investigate the correctness of the 3D processing maps, and the optimal forming range of the GW93 alloy was determined. The results obtained in this study have important reference value for developing a process of magnesium alloy plastic forming.

\section{Isothermal Compression Tests of GW93 Alloy}

2.1. Test Scheme. The chemical composition of the GW93 alloy is Mg-9Gd-3Y (in wt.\%), and isothermal compression tests were carried out to investigate its hot deformation behavior. The material used in the isothermal compression tests was a semicontinuously cast $\operatorname{rod}(\Phi 100 \mathrm{~mm} \times 500 \mathrm{~mm})$. The homogenization was performed at $500^{\circ} \mathrm{C}$ for $5 \mathrm{~h}$. The microstructure of the GW93 alloy after homogenization is shown in Figure 1. As can be seen, the alloy after treatment exhibits an equiaxed microstructure with an average grain size of approximately $124.8 \mu \mathrm{m}$.

Cylinders with the size of $\Phi 8 \mathrm{~mm} \times 10 \mathrm{~mm}$ were cut by wire-electrode cutting along the axial direction of the test material as the hot compression test samples, and compression tests were performed at different temperatures and

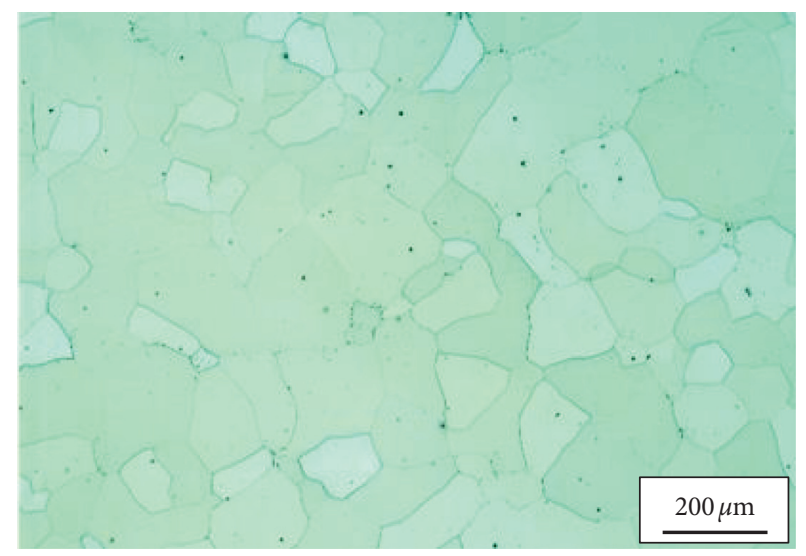

Figure 1: Microstructure of GW93 alloy after homogenization.

different strain rates using the Gleeble 1500D thermal simulation testing machine. The compression temperature varied from $300^{\circ} \mathrm{C}$ to $450^{\circ} \mathrm{C}$, and the strain rate varied from 0.001 to $1 \mathrm{~s}^{-1}$. All samples were deformed to the true strain of 1.0. Prior to the deformation, 16 groups of tests were carried out and the test parameters are listed in Table 1. Before the tests were performed, the top and bottom surfaces of each specimen were coated with graphite to improve the lubrication effect.

The specimens were heated to their respective deformation temperature at a constant rate of $5^{\circ} \mathrm{C} / \mathrm{s}$ and then kept warm for $5 \mathrm{~min}$. Subsequently, compression tests were carried out with different strain rates. When the compression tests finished, the samples were rapidly quenched to retain the corresponding hot deformed microstructure. The process control of the hot compression tests and the data collected from the test results were completed using a personal computer.

\subsection{Flow Characteristics and Deformation Mechanisms.}

The flow stress curves of the GW93 alloy obtained under isothermal hot compression at different deformation temperatures are shown in Figure 2. As can be seen, the deformation temperature and the strain rate have obvious effects on the flow stress. In Figure 2, it can be seen that the flow stress obviously increases with the decrease of temperature or the increase of strain rate. The shapes of the flow stress curves indicate the competing deformation mechanisms of work hardening, dynamic recovery, and dynamic recrystallization [23]. In the initial deformation stage, dislocations start to accumulate, entangle, and pile up, leading to obvious work hardening. Moreover, because the stacking fault energy of the investigated superalloy is relatively low, the dynamic recovery caused by dislocation cross-slip and climb is too weak to balance the work hardening. Hence, the flow stress rapidly increases. As the deformation continues, dynamic recrystallization occurs when the dislocations accumulate to a critical value [24]. The nucleation and growth of dynamic recrystallized grains can cause the annihilation of dislocation, which leads to the decrease of the work hardening rate. After rising to the peak stress, obvious dynamic softening is induced by the dynamic 
TABle 1: Process parameters of hot compression tests.

\begin{tabular}{lr}
\hline Process parameters & Parameter value \\
\hline Deformation temperature $T\left({ }^{\circ} \mathrm{C}\right)$ & $300,350,400,450$ \\
Strain rate $\dot{\varepsilon}\left(\mathrm{s}^{-1}\right)$ & $0.001,0.01,0.1,1$ \\
True strain $\varepsilon$ & 1 \\
\hline
\end{tabular}

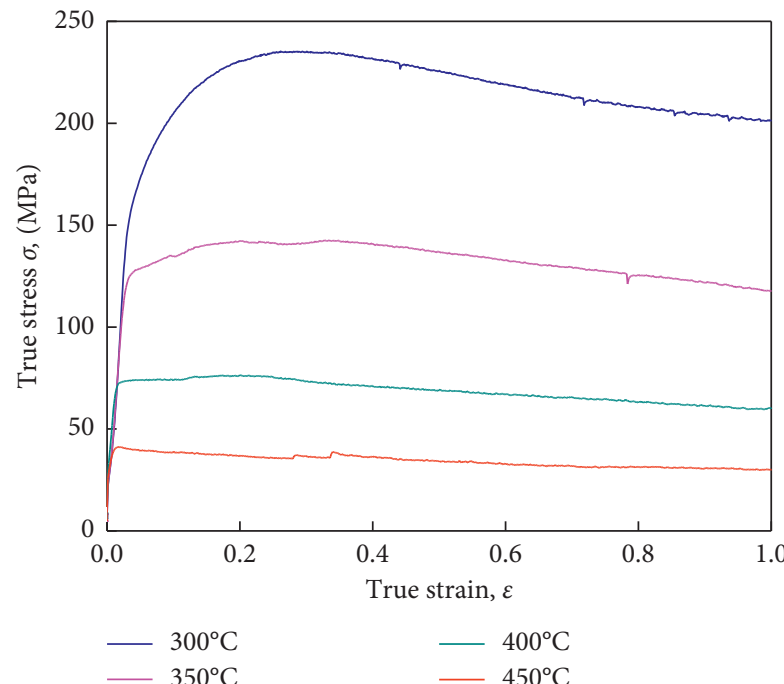

(a)

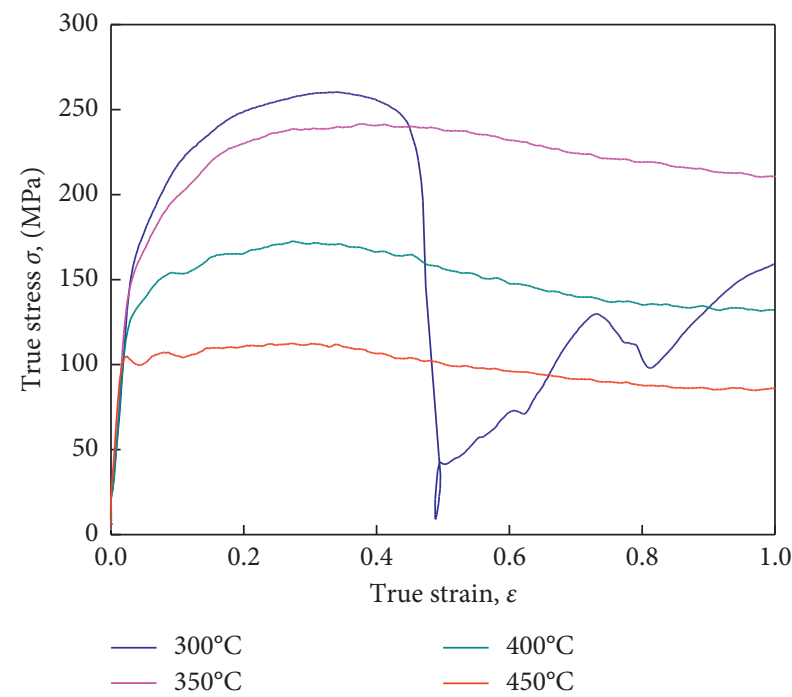

(c)

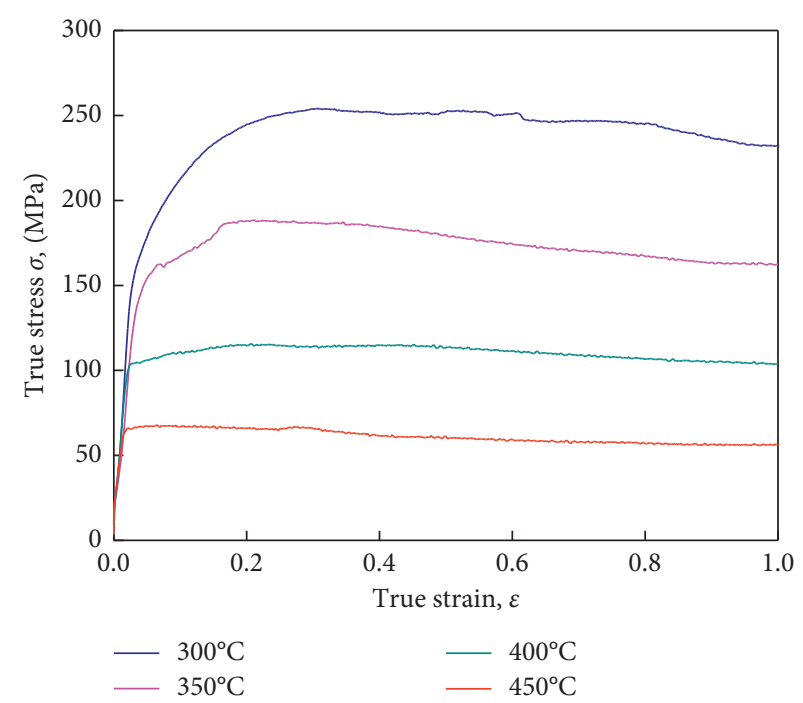

(b)

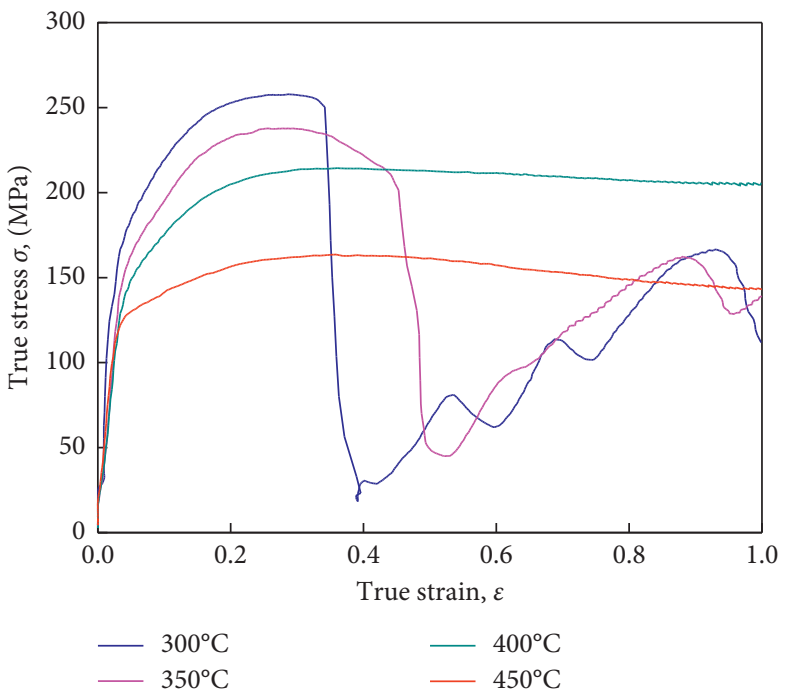

(d)

FIgURE 2: True stress-strain curves of GW93 alloy at different strain rates: (a) $\dot{\varepsilon}=0.001 \mathrm{~s}^{-1}$; (b) $\dot{\varepsilon}=0.01 \mathrm{~s}^{-1}$; (c) $\dot{\varepsilon}=0.1 \mathrm{~s}^{-1}$; (d) $\dot{\varepsilon}=1 \mathrm{~s}^{-1}$.

recrystallization, and the curve begins to decline. Finally, steady-state flow behavior can be obtained when the work hardening and dynamic softening achieve a dynamic balance $[23,25]$.

At the strain rate of $0.1 \mathrm{~s}^{-1}$, local cracking occurred in the compression process of the specimen at $300^{\circ} \mathrm{C}$, which caused the sharp decrease of the flow stress curve after its increase. When the crack gap was gradually eliminated in the subsequent compression process, the flow stress curve increased with the work hardening. At the strain rate of $1 \mathrm{~s}^{-1}$, the fluctuation phenomenon of the flow stress curves at $300^{\circ} \mathrm{C}$ and $350^{\circ} \mathrm{C}$ was caused for the same reason.

\section{Construction and Analysis of 3D Processing Maps}

The 3D processing maps can be established based on dynamic material models and stress-strain curves, which consist of two parts: a $3 \mathrm{D}$ power dissipation map and a $3 \mathrm{D}$ flow instability map, delineating the variations of the 
efficiency of power dissipation and the regions of flow instability under different forming conditions. The 3D processing maps reflect the variation of the power dissipation coefficient and the size of the flow instability region with the deformation temperature, strain rate, and strain.

3.1. 3D Power Dissipation Map. In the hot deformation process, the total power $P$ input by the external force consists of two complementary parts and is expressed as follows $[26,27]$ :

$$
P=\sigma \cdot \dot{\varepsilon}=G+J=\int_{0}^{\dot{\varepsilon}} \sigma \mathrm{d} \dot{\varepsilon}+\int_{0}^{\sigma} \dot{\varepsilon} \mathrm{d} \sigma
$$

where $G$ represents the power dissipated by the plastic deformation, most of which is transformed into viscoplastic heat; $J$ represents the power dissipation through the microstructure evolution.

Under the condition of constant forming temperature and strain, the flow stress is assumed to conform to the dynamic material model, as follows:

$$
\sigma=K \dot{\varepsilon}^{m}
$$

where $K$ is a material constant and $m$ is the strain rate sensitivity index.

$$
m=\frac{\partial \ln \sigma}{\partial \ln \dot{\varepsilon}} .
$$

During the hot deformation, the proportion of $G$ and $J$ is governed by the constitutive flow behavior of the material and defined as the strain rate sensitivity index $(m)$, as follows:

$$
\frac{\mathrm{d} J}{\mathrm{~d} G}=\frac{\dot{\varepsilon}}{\sigma} \frac{\mathrm{d} \sigma}{\mathrm{d} \dot{\varepsilon}}=\frac{\mathrm{d} \ln \sigma}{\mathrm{d} \ln \dot{\varepsilon}}=m .
$$

By comparing $J$ with its maximum values $J_{\max }$, the efficiency of power dissipation $\eta$ is defined and can be written as follows $[22,28]$ :

$$
\eta=\frac{J}{J_{\max }}=\frac{2 m}{m+1}
$$

Essentially, the parameter $\eta$ describes the microdeformation mechanism of the workpiece in the range of the applied temperature and strain rate. From the true stressstrain curves in Figure 2, the flow stress values under the constant strain rates and temperatures at different strains can be extracted. Then, the values of the strain rate sensitivity index $m$ and power dissipation coefficient $\eta$ can be calculated and obtained [22]. The 3D power dissipation map and 3D flow instability map must be established based on the dynamic material models and stress-strain curves, respectively, to reflect the distribution of the power dissipation coefficient and flow instability parameters in 3D space of the temperature, strain rate, and strain. Subsequently, by considering the temperature, strain rate, and strain as the $3 \mathrm{D}$ coordinate axis, the $3 \mathrm{D}$ power dissipation map was created using the MATLAB software, as shown in Figure 3. The color code on the right side of Figure 3 indicates that different

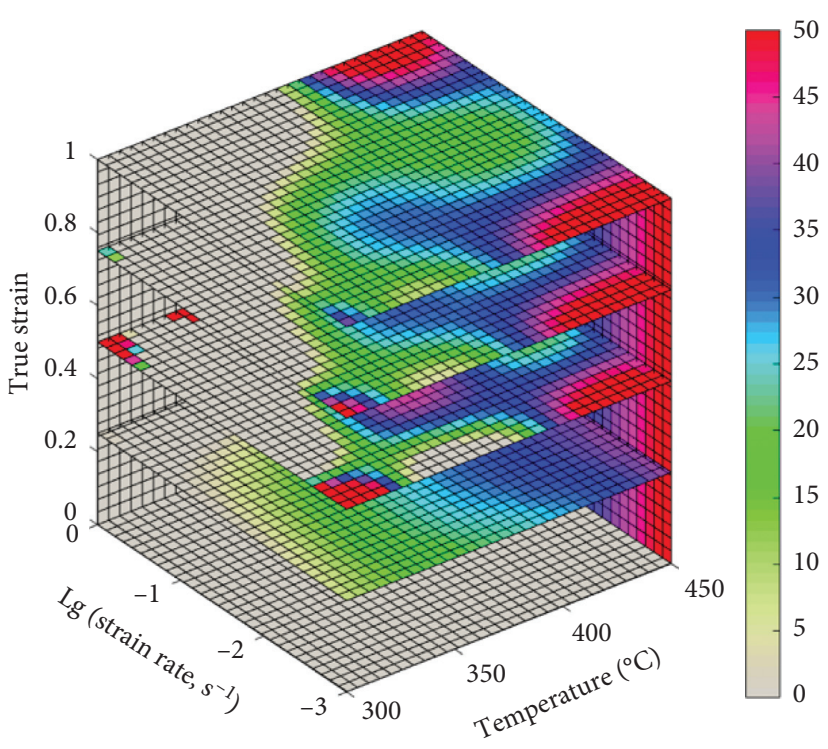

Figure 3: 3D power dissipation map.

colors correspond to different power dissipation coefficient percentages, and the grid color of each point indicates the efficiency of power dissipation.

As shown in Figure 3, the power dissipation coefficient varies with the change of the strain, temperature, and strain rate, which indicates that the three parameters exert great influence on the power dissipation coefficient. The variation trend of the power dissipation coefficient with hot process parameters indicates that the power dissipation coefficient increases with the increase of the deformation temperature or the decrease of the strain rate. The power dissipation coefficient is higher in the region of high temperature and low strain rate. As the power dissipation efficiency increases, the proportion of energy input to the evolution of the structure becomes larger. Such areas are most beneficial for plastic deformation, and the formability is improved [29]. Additionally, it can be seen that when the temperature was $300^{\circ} \mathrm{C}$ and the strain rate was $1 \mathrm{~s}^{-1}$, the power dissipation coefficient was minimum and the formability was the most inferior; when the temperature was $450^{\circ} \mathrm{C}$ and the strain rate was $0.001 \mathrm{~s}^{-1}$, the power dissipation coefficient became maximum and the formability was optimal. According to the $3 \mathrm{D}$ power dissipation map, the optimal region of the hot deformation parameters was determined in the temperature range of $380-450^{\circ} \mathrm{C}$ and strain rate range of $0.001-0.01 \mathrm{~s}^{-1}$.

3.2. 3D Flow Instability Map. Apart from the power dissipation map, it is necessary to establish the $3 \mathrm{D}$ flow instability map to more extensively analyze the formability of the GW93 alloy. It has been proven that the Murty instability criterion is applicable to many types of flow curves [30, 31]; therefore, the Murty instability criterion was used for establishing the 3D flow instability map of the GW93 alloy. The Murty instability criterion can be expressed as follows: 


$$
2 m-\eta<0
$$

The 3D flow instability map of the GW93 alloy is shown in Figure 4, wherein the white areas represent safety regions and the grey areas represent instability regions. The flow instability will appear in the grey area of the instability map, which should be avoided in the forming process.

As shown in Figure 4, the flow instability of the material occurred only in the low temperature range of $300-350^{\circ} \mathrm{C}$, which indicates that the flow instability is more likely to occur at lower temperature.

In summary, compared with the power dissipation region and flow instability region, the optimal forging process parameters of the GW93 alloy are the deformation temperatures of $380-450^{\circ} \mathrm{C}$ and the strain rates of $0.001-0.01 \mathrm{~s}^{-1}$.

\section{Formability Analysis of GW93 Alloy}

As can be seen in Figures 3 and 4, the formability of the material at high strain rate is somewhat different from that at low strain rate in the same deformation temperature range. In other words, when the temperature is constant, the flow instability is more likely to occur at a higher strain rate. This results from the large number of dislocations piling up in the process of plastic deformation, and insufficient dynamic softening can easily cause local severe plastic deformation. Flow instability can easily cause an adiabatic shear band and even crack initiation. To verify this, the hot deformation physical model and the 3D processing maps were imported into DEFORM-3D and the isothermal plane strain forging simulation was carried out. Additionally, the corresponding isothermal plane strain forging technological experiment was performed. The results of the numerical simulation and forging technological experiment were compared to analyze the formability of the GW93 alloy and validate the hot deformation physical model and 3D processing maps.

\subsection{FE Simulation of Isothermal Plane Strain Forging Process.} The schematic illustration of the FE model of the isothermal plane strain forging process is shown in Figure 5. To improve the function of the microstructure prediction in the forming simulation, the hot deformation physical model and the 3D processing maps of the GW93 alloy were coupled to DEFORM-3D through a secondary development using the Fortran language. The cuboid GW93 alloy sample with a length of $10 \mathrm{~mm}$ in, width of $10 \mathrm{~mm}$, and height of $10 \mathrm{~mm}$ was used in the FE simulation. Owing to the symmetry of the FE model along the $X Y$ plane, only half of the workpiece was simulated to reduce the simulation time. The simulated temperatures of the workpiece, dies, and ambient air were set to $380^{\circ} \mathrm{C}$. The downward speed of the upper die was set to $0.51 \mathrm{~mm} / \mathrm{s}$. Coulomb friction was used to simulate the contact and the friction coefficient was set to 0.22 .

After the simulation, a cut along the $Y Z$ symmetry plane of the sample was made, and 1/4 of the sample was taken for observation and analysis to determine the distribution of safe deformation regions and instability regions. Figure 6 shows the evolution of the flow instability region during the

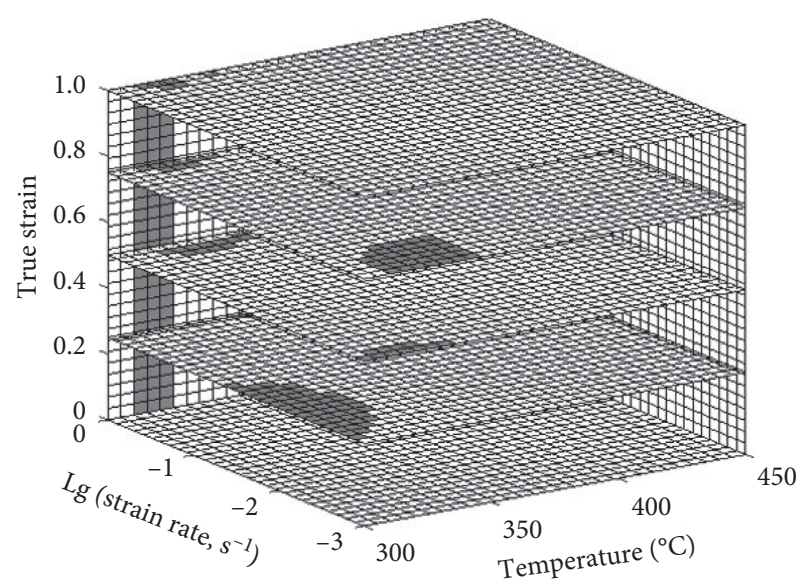

FIGURE 4: 3D flow instability map of GW93 alloy.

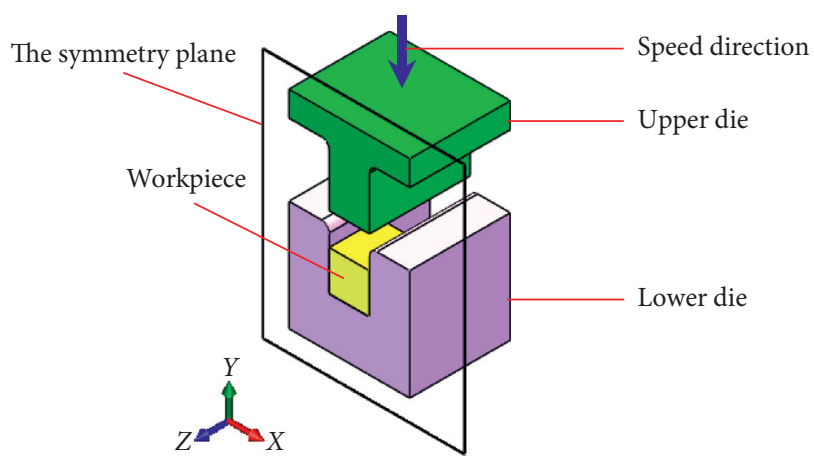

FIgURE 5: Schematic illustration of FE model of isothermal plane strain forging process.

hot forming process, wherein the red areas represent safety regions and the green areas represent flow instability regions. As shown in Figure 6, the flow instability regions only appeared at the upper and lower corners of the workpiece at the initial stage of compression and then appeared at the central part. As the deformation proceeded, the height of the workpiece decreased, the downward speed remained unchanged, and the strain rate of the workpiece gradually increased, which resulted in the continuous expansion of the flow instability regions. When the extrusion reduction reached $6.4 \mathrm{~mm}$, the area of the flow instability regions became maximum. Figure 7 shows the distribution of the equivalent strain rate after deformation. As shown in Figure 6(e), the flow instability region was mainly concentrated in the area with a high strain rate, and no flow instability region emerged in the area with a low strain rate. The simulation results revealed that the formability of the material at a low strain rate is better compared with that at high strain rate under the same deformation temperature.

\subsection{Experimental Verifications of Safety Region and Instability} Region. An isothermal plane strain forging technological experiment was carried out to verify the reliability of the abovementioned simulation results. The experimental parameters and the dimensions of the sample were the same as those in the FE simulation. When the experiment was 


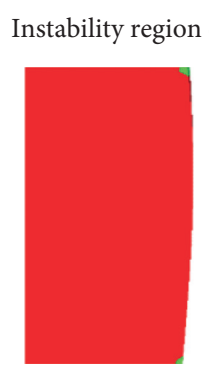

(a)
Instability region distribution

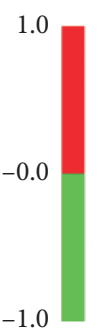

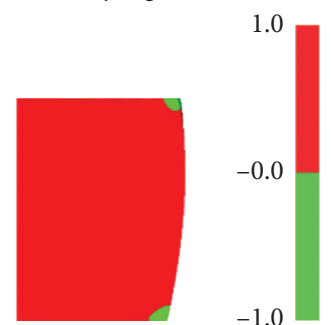

(b)
Instability region distribution

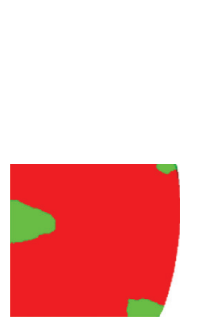

(c)

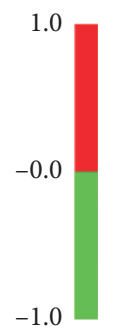

Instability region distribution

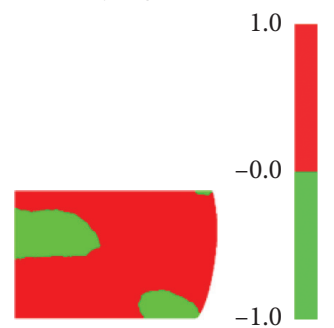

(d)

Instability region distribution

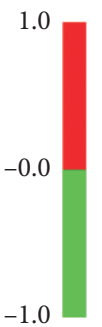

(e)

Figure 6: Distributions of flow instability regions under different extrusion reductions: (a) $1.3 \mathrm{~mm}$; (b) $2.5 \mathrm{~mm}$; (c) $3.8 \mathrm{~mm}$; (d) $5 \mathrm{~mm}$; (e) $6.4 \mathrm{~mm}$.

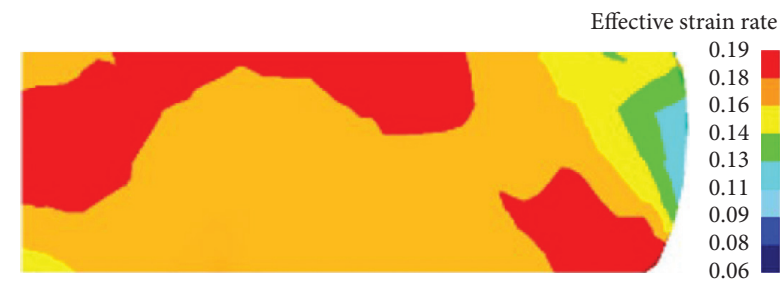

FIGURE 7: Equivalent strain rate distribution of workpiece.

finished, the workpiece was immediately quenched to retain its deformation microstructure. Figure 8(a) shows the macroscopic appearance of the deformed workpiece from the front and back view, and Figure 8(b) shows the quarter part obtained after cutting along the symmetry plane of the length and width of the workpiece. By comparing Figures $6(\mathrm{e})$ and $8(\mathrm{~b})$, it can be seen that the shape of the workpiece after the experiment is essentially the same as that after the simulation.

After grinding and polishing, 1/4 of the workpiece was corroded with a mixture of $10 \mathrm{~mL}$ of acetic acid, $4.2 \mathrm{~g}$ of picric acid, $10 \mathrm{~mL}$ of distilled water, and $70 \mathrm{~mL}$ of alcohol for $20 \mathrm{~s}$. Based on the distribution of the flow instability region shown in Figure 6(e), six areas were selected on the cutting plane of the workpiece used in the microstructure investigation, as shown in Figure 9(a), and the microstructure of each area was observed. In Figure 9(a), regions I-III are located in the instability region at high strain rate and regions IV-VI are located in the safety region at low strain rate. The dotted line at approximately $45^{\circ}$ to the principal stress axis in Figure 9(a) represents the distribution direction of the maximum flow instability region, which is essentially

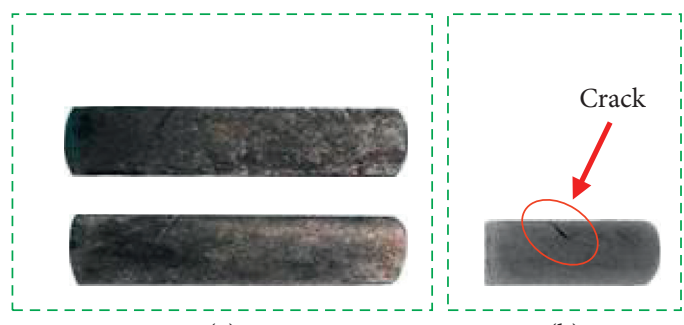

(a)

(b)

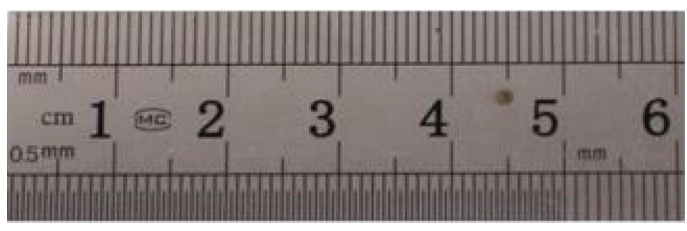

FIgURE 8: Appearance of workpiece after experiment: (a) before cutting; (b) after cutting.

consistent with the location and direction of the macrocracks shown in Figure 8(b). As shown in Figures 9(b)-9(d), the material underwent severe inhomogeneous deformation. The adiabatic shear bands can be clearly observed and macroscopic cracks appeared in region I. As shown in Figures $9(\mathrm{e})-9(\mathrm{~g})$, the material was not damaged in these areas. Additionally, the material contains numerous twins within grains, and fine dynamic recrystallization grains appear at the grain boundary, particularly at the grain boundary triple junction.

In conclusion, the experimental results are in good agreement with the simulation results, which confirms the reliability of the simulation results, the accuracy of the hot deformation physical model, and the 3D processing maps. 


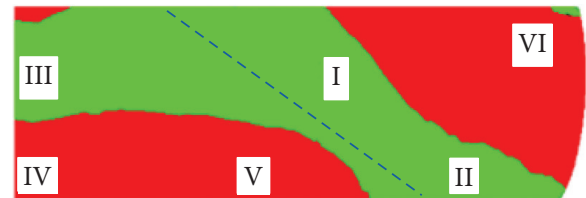

(a)

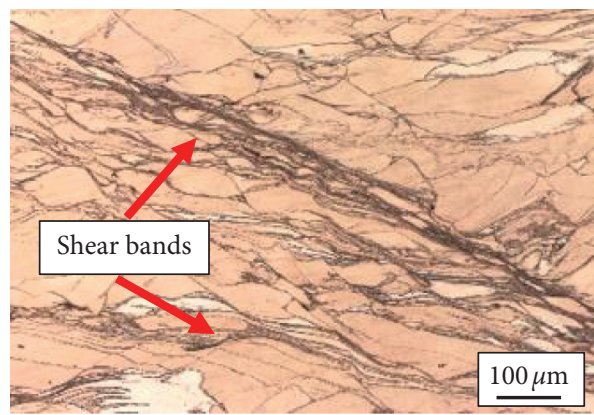

(c)

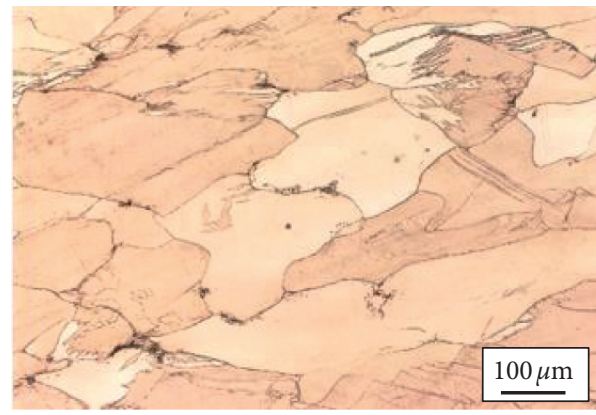

(e)

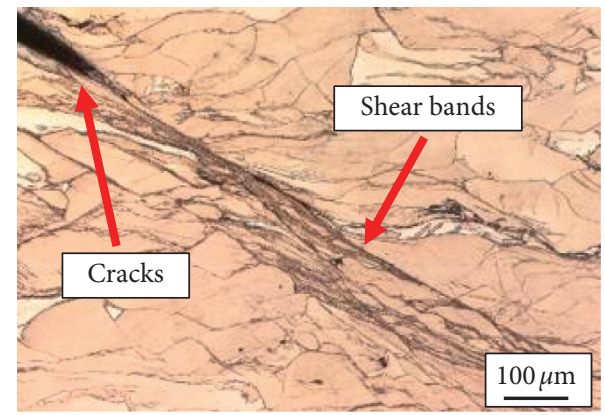

(b)

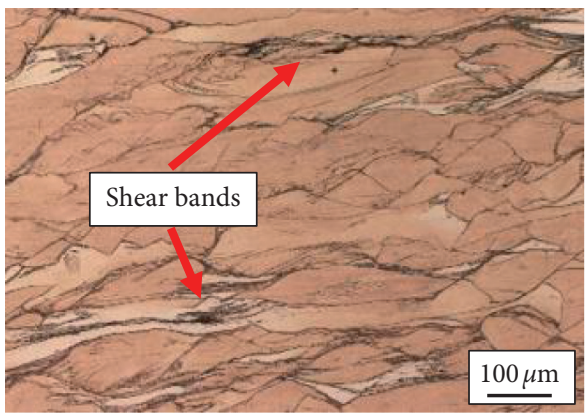

(d)

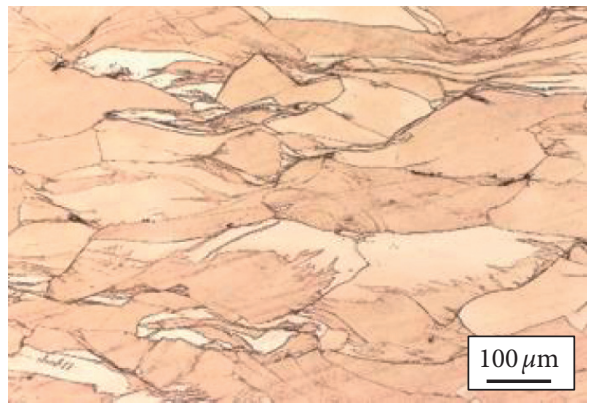

(f)

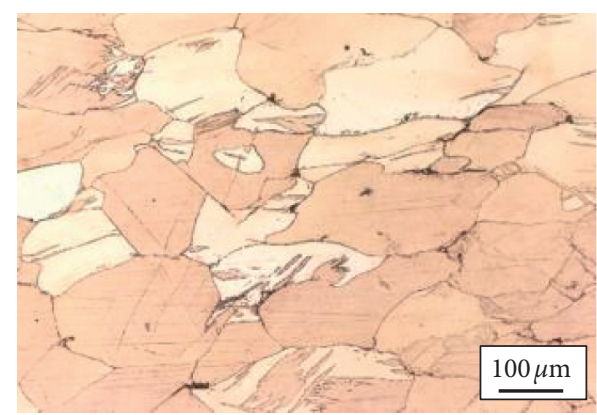

(g)

Figure 9: (a) Location of six areas for metallographic observation; (b) microstructure of region I; (c) microstructure of region II; (d) microstructure of region III; (e) microstructure of region IV; (f) microstructure of region V; (g) microstructure of region VI.

\section{Conclusions}

The following conclusions were drawn from this study:

(1) The 3D processing maps of the GW93 alloy were established. The process parameter domain suitable for the forging of the cast GW93 alloy is in the temperature range of $380-450^{\circ} \mathrm{C}$ and strain rate range of $0.001-0.01 \mathrm{~s}^{-1}$.

(2) By means of user subroutines, the 3D processing maps were coupled to the DEFORM-3D FE software. A formability simulation of the isothermal plane strain forging process was carried out, and the 
simulation results were used in conjunction with the results of the isothermal plane strain forging technological experiment to verify the accuracy of the $3 \mathrm{D}$ processing maps.

(3) In the isothermal plane strain forging technological experiment, dynamic recrystallization occurred in the parameters of the safety region, and adiabatic shear bands and macroscopic cracks appeared in the instability region.

\section{Data Availability}

The data used to support the findings of this study are included in the article.

\section{Conflicts of Interest}

The authors declare that they have no conflicts of interest.

\section{Authors' Contributions}

Conceptualization was carried out by P.L. and J.L.; methodology was performed by P.L. and J.L.; software was by P.L.; validation was done P.L.; formal analysis was carried out by P.L. and J.L.; investigation was performed by P.L.; resources were obtained by P.L.; data was curated by P.L.; the original draft was prepared by P.L.; review and editing were done by J.L.; visualization was carried out by P.L.; supervision was by P.L.; project administration was done by P.L. and J.L. All authors have read and agreed to the published version of the manuscript.

\section{Acknowledgments}

This study was funded by the National Natural Science Foundation of China (51804120), Natural Science Foundation of Hebei Province for Youth (E2019508144), and Fundamental Research Funds for the Central Universities (3142018012, 3142019055, and 3142018006).

\section{References}

[1] Y. Cai, C. Y. Sun, W. R. Wang, Y. L. Li, L. Wan, and L. Y. Qian, "An isothermal forming process with multi-stage variable speed for magnesium component assisted by sensitivity analysis," Materials Science \& Engineering A, vol. 729, pp. 9-20, 2018.

[2] L. Deng, X. Wang, J. Jin, and J. Xia, "Precision forging technology for aluminum alloy," Frontiers of Mechanical Engineering, vol. 13, no. 1, pp. 25-36, 2018.

[3] H.-x. Li, K. Wang, R. Luo et al., "Influence of radial forging process on strain inhomogeneity of hollow gear shaft using finite element method and orthogonal design," Journal of Central South University, vol. 27, no. 6, pp. 1666-1677, 2020.

[4] L. Yuan, Z. Zhao, W. Shi, F. Xu, and D. Shan, "Isothermal forming of the large-size AZ80A magnesium alloy forging with high mechanical properties," International Journal of Advanced Manufacturing Technology, vol. 78, no. 9-12, pp. 2037-2047, 2015.

[5] B. Li, B. Teng, and W. Xu, "Hot deformation characterization of homogenized $\mathrm{Mg}-\mathrm{Gd}-\mathrm{Y}-\mathrm{Zn}-\mathrm{Zr}$ alloy during isothermal compression," The Journal of The Minerals, Metals \& Materials Society, vol. 71, no. 11, pp. 4059-4070, 2019.

[6] W. Liu, B. Zhou, G. Wu, L. Zhang, X. Peng, and L. Cao, "High temperature mechanical behavior of low-pressure sand-cast Mg-Gd-Y-Zr magnesium alloy," Journal of Magnesium and Alloys, vol. 7, no. 4, pp. 597-604, 2019.

[7] J. Zeng, X. Wei, S. Dong, F. Wang, Li Jin, and J. Dong, “3D processing maps of cast Mg-8Gd-3Y alloy at high strain rates and their application in plane strain forging," International Journal of Advanced Manufacturing Technology, vol. 106, no. 1-2, pp. 133-141, 2020.

[8] W. Wang, S. Chen, K. Tao, K. Gao, and X. Wei, "Experimental investigation of limit drawing ratio for AZ31B magnesium alloy sheet in warm stamping," International Journal of Advanced Manufacturing Technology, vol. 92, no. 1-4, pp. 723731, 2017.

[9] H. T. Kang and O. Terry, "Mechanical behavior of cast and forged magnesium alloys and their microstructures," Materials Science \& Engineering A, vol. 490, no. 1, pp. 52-56, 2008.

[10] J. Zeng, F. Wang, X. Wei, S. Dong, Z. Zhang, and J. Dong, “A new constitutive model for thermal deformation of magnesium alloys," Metallurgical and Materials Transactions A, vol. 51, no. 1, pp. 497-512, 2020.

[11] R. Alizadeh, R. Mahmudi, O. A. Ruano, and A. H. W. Ngan, "Constitutive analysis and hot deformation behavior of finegrained Mg-Gd-Y-Zr alloys," Metallurgical and Materials Transactions A, vol. 48, no. 11, pp. 5699-5709, 2017.

[12] R. Alizadeh, R. Mahmudi, A. H. W. Ngan, Y. Huang, and T. G. Langdon, "Superplasticity of a nano-grained Mg-Gd-Y$\mathrm{Zr}$ alloy processed by high-pressure torsion," Materials Science and Engineering: A, vol. 651, pp. 786-794, 2016.

[13] X. Chen, Q. Li, J. Chen, and L. Zhu, "Microstructure and mechanical properties of Mg-Gd-Y-Sm-Al alloy and analysis of grain refinement and strengthening mechanism," Journal of Rare Earths, vol. 37, no. 12, pp. 1351-1358, 2019.

[14] C. Xu, M. Zheng, S. Xu et al., "Improving strength and ductility of $\mathrm{Mg}-\mathrm{Gd}-\mathrm{Y}-\mathrm{Zn}-\mathrm{Zr}$ alloy simultaneously via extrusion, hot rolling and ageing," Materials Science and Engineering: A, vol. 643, pp. 137-141, 2015.

[15] L. Lu, C. Liu, Z. Yin, J. Zhao, Lu Gan, and Z. Wang, "Double extrusion of Mg-Al-Zn alloys," International Journal of Advanced Manufacturing Technology, vol. 89, no. 1-4, pp. 869875, 2017.

[16] C. Sun, Yu Xiang, G. Liu, X. Zuo, M. Wang, and Q. Zhang, "Extrusion limit diagram of IN 690 super-alloy tube based on hot processing map," International Journal of Advanced Manufacturing Technology, vol. 89, no. 9-12, pp. 3419-3428, 2017.

[17] Q. Liao, Y. Jiang, Q. Le et al., "Hot deformation behavior and processing map development of AZ110 alloy with and without addition of La-rich Mish Metal," Journal of Materials Science \& Technology, vol. 61, pp. 1-15, 2021.

[18] X. Shang, J. Zhou, X. Wang, and Y. Luo, "Optimizing and identifying the process parameters of AZ31 magnesium alloy in hot compression on the base of processing maps," Journal of Alloys and Compounds, vol. 629, pp. 155-161, 2015.

[19] J.-Q. Li, J. Liu, and Z.-S. Cui, "Hot deformation stability of extruded AZ61 magnesium alloy using different instability criteria," Acta Metallurgica Sinica, vol. 28, no. 11, pp. 1364-1372, 2015.

[20] J. Li, J. Liu, and Z. Cui, "Characterization of hot deformation behavior of extruded ZK60 magnesium alloy using 3D processing maps," Materials \& Design (1980-2015), vol. 56, pp. 889-897, 2014. 
[21] S. Anbuselvan and S. Ramanathan, "Hot deformation and processing maps of extruded ZE41A magnesium alloy," Materials \& Design (1980-2015), vol. 31, no. 5, pp. 2319-2323, 2010.

[22] J. Liu, J.-q. Li, Z.-s. Cui, H.-a. Ou, and L.-q. Ruan, "Material driven workability simulation by FEM including 3D processing maps for magnesium alloy," Transactions of Nonferrous Metals Society of China, vol. 23, no. 10, pp. 3011-3019, 2013.

[23] Y.C. Lina, X.-Y. Wuab, X.-M. Chen et al., "EBSD study of a hot deformed nickel-based superalloy," Journal of Alloys and Compounds, vol. 640, pp. 101-113, 2015.

[24] Y.-Q. Jiang, Y. C. Lin, X.-Y. Zhang, C. Chen, Q.-W. Wang, and G.-D. Pang, "Isothermal tensile deformation behaviors and fracture mechanism of Ti-5Al-5Mo-5V-1Cr-1Fe alloy in $\beta$ phase field," Vacuum, vol. 156, pp. 187-197, 2018.

[25] H. Zhang, K. Zhang, S. Jiang, H. Zhou, C. H. Zhao, and $\mathrm{X}$. Yang, "Dynamic recrystallization behavior of a $\gamma$ '-hardened nickel-based superalloy during hot deformation," Journal of Alloys and Compounds, vol. 623, pp. 374-385, 2015.

[26] Y. V. R. K. Prasad and T. Seshacharyulu, "Processing maps for hot working of titanium alloys," Materials Science and Engineering: A, vol. 243, no. 1-2, pp. 82-88, 1998.

[27] Y. V. R. K. Prasad and K. P. Rao, "Effect of homogenization on the hot deformation behavior of cast AZ31 magnesium alloy," Materials \& Design, vol. 30, no. 9, pp. 3723-3730, 2009.

[28] M. Shalbafi, R. Roumina, and R. Mahmudi, "Hot deformation of the extruded $\mathrm{Mg}-10 \mathrm{Li}-1 \mathrm{Zn}$ alloy: constitutive analysis and processing maps," Journal of Alloys and Compounds, vol. 696, pp. 1269-1277, 2016.

[29] Z. Du, S. Jiang, and K. Zhang, "The hot deformation behavior and processing map of Ti-47.5Al-Cr-V alloy," Materials \& Design, vol. 86, no. 5, pp. 464-473, 2015.

[30] S. Murty and B. N. Rao, "On the development of instability criteria during hotworking with reference to IN 718," $\mathrm{Ma}$ terials Science \& Engineering A, vol. 254, no. 1-2, pp. 76-82, 1998.

[31] M. Xiong, W. Zeng, B. Xu, S. Yu, X. Chen, and Y. Hana, "Characterization of the hot deformation behavior of a $\mathrm{Ti}-22 \mathrm{Al}-25 \mathrm{Nb}$ alloy using processing maps based on the Murty criterion," Intermetallics, vol. 20, no. 1, pp. 1-7, 2012. 